\title{
HUBUNGAN PENGETAHUAN IBU TENTANG MANAJEMEN LAKTASI DAN DUKUNGAN KELUARGA DENGAN PEMBERIAN ASI EKSKLUSIF PADA BAYI USIA 0-6 BULAN
}

\author{
Nur Afrinis ${ }^{1}$, Indrawati ${ }^{2}$, Noni Haspriyanti ${ }^{3}$ \\ Prodi S1 Gizi, FIK, Universitas Pahlawan Tuanku Tambusai ${ }^{1,3}$ \\ Prodi S1 Keperawatan, FIK, Universitas Pahlawan Tuanku Tambusai ${ }^{2}$ \\ Afrinis.eva@gmail.com ${ }^{1}$, indrawatiigo@gmail.com ${ }^{2}$
}

\begin{abstract}
Exclusive breastfeeding for infants aged 0-6 months has a major contribution to optimal growth and development and immunity of infants. Mother and family play an important role in exclusive breastfeeding. The purpose of this study was to analyze the relationship between maternal knowledge about lactation management and family support with exclusive breastfeeding for infants aged 0-6 months in the work area of the Senapelan Community Health Center in 2020. This type of research is a quantitative study with a cross sectional design. The study was conducted on April - June 2020 with a total sample of 38 primiparous mothers who had babies aged 6-12 months which were obtained using purposive sampling technique. Data collection using a questionnaire. The data analysis used was univariate and bivariate analysis with the Chi Square test. The results of univariate analysis showed that 20 respondents (52.6\%) had less knowledge about lactation management, 24 respondents (63.2\%) did not get support from their families and 21 respondents (55.3\%) did not exclusively breastfeed babies aged 0- 6 months. The results of the Chi Square test showed a relationship between maternal knowledge about lactation management $(p$ value $=0.024)$ and family support ( $p$ value $=$ 0.029) with exclusive breastfeeding for infants aged 0-6 months. There is a significant relationship between maternal knowledge about lactation management and family support with exclusive breastfeeding for infants aged 0-6 months in the working area of the Senapelan Community Health Center in 2020. Pregnant women and breastfeeding mothers should actively participate in counseling activities and practices in increasing knowledge about lactation management. and health workers actively socialize to the community so that families can support exclusive breastfeeding, especially for primiparous mothers.
\end{abstract}

Keywords : Exclusive breastfeeding, family support, lactation management, maternal knowledge

\begin{abstract}
ABSTRAK
Pemberian ASI eksklusif pada bayi usia 0-6 bulan memiliki kontribusi yang besar terhadap tumbuh kembang optimal dan daya tahan tubuh bayi. Ibu dan keluarga berperan penting dalam pemberian ASI eksklusif. Tujuan penelitian ini untuk menganalisis hubungan pengetahuan ibu tentang manajemen laktasi dan dukungan keluarga dengan pemberian ASI eksklusif pada bayi usia 0-6 bulan di wilayah kerja Puskesmas Senapelan tahun 2020. Jenis penelitian adalah penelitian kuantitatif dengan desain cross sectional. Penelitian dilakukan pada tanggal 29 Mei-9 Juni 2020 dengan jumlah sampel 38 orang ibu primipara yang memiliki bayi usia 6-12 bulan diperoleh menggunakan teknik purposive sampling. Pengumpulan data menggunakan kuesioner. Analisa data yang digunakan adalah analisa univariat dan bivariat dengan uji Chi Square. Hasil analisa univariat diperoleh 20 responden $(52,6 \%)$ memiliki pengetahuan kurang tentang manajemen laktasi, 24 responden $(63,2 \%)$ tidak mendapat dukungan dari keluarga dan 21 responden (55,3\%) tidak memberikan ASI eksklusif pada bayi usia 06 bulan. Hasil uji Chi Square ada hubungan antara pengetahuan ibu tentang manajemen laktasi ( $p$ value $=0,024$ ) dan dukungan keluarga $(p$ value $=0,029$ ) dengan pemberian ASI eksklusif pada bayi usia 0-6 bulan. Terdapat hubungan yang signifikan antara pengetahuan ibu tentang manajemen laktasi dan dukungan keluarga dengan pemberian ASI eksklusif pada bayi usia 0-6 bulan di wilayah kerja Puskesmas Senapelan tahun 2020. Ibu hamil dan ibu menyusui agar aktif mengikuti kegiatan penyuluhan dan praktik dalam meningkatkan pengetahuan
\end{abstract}


tentang manajemen laktasi dan petugas kesehatan aktif melakukan sosialisasi kepada masyarakat sehingga keluarga dapat mendukung pemberian ASI eksklusif khususnya pada ibu primipara

Kata kunci $\quad$ : ASI Eksklusif, Dukungan Keluarga, Manajemen Laktasi, Pengetahuan Ibu

\section{PENDAHULUAN}

Bayi baru lahir belum memiliki sistim pencernaan yang sempurna sehingga jenis makanan yang dikonsumsi harus disesuaikan dengan kondisi tubuh bayi. Bayi hanya membutuhkan Air Susu Ibu (ASI) untuk pertumbuhan selama 6 bulan pertama dan ASI adalah makanan yang paling sempurna bagi bayi. Tidak ada cairan lain apapun yang dapat menggantikan ASI. Kandungan zat gizi dalam ASI sesuai dengan kebutuhan dan saluran cerna bayi (Cox, 2004 dalam Sudargo, 2019).

Peraturan Pemerintah Nomor 33 Tahun 2012 tentang Pemberian Air Susu Ibu Eksklusif menjelaskan ASI eksklusif adalah ASI yang diberikan kepada bayi sejak dilahirkan selama enam bulan tanpa menambahkan dan/atau mengganti dengan makanan atau minuman lain. Berdasarkan Pasal 6 dalam peraturan pemerintah yang sama, setiap ibu yang melahirkan harus memberikan ASI eksklusif kepada bayi yang dilahirkannya. Namun hal ini menjadi tidak berlaku jika terdapat indikasi medis, ibu tidak ada, atau ibu terpisah dari bayinya.

ASI eksklusif memiliki kontribusi yang besar terhadap tumbuh kembang dan daya tahan tubuh bayi. Bayi yang diberi ASI eksklusif akan tumbuh dan berkembang secara optimal dan tidak mudah sakit. Hal tersebut sesuai dengan beberapa kajian dan fakta global. Kajian global "The Lancet Breastfeeding Series", tahun 2016 telah membuktikan: 1) Menyusui eksklusif menurunkan angka kematian karena infeksi sebanyak $88 \%$ pada bayi berusia kurang dari 3 bulan, 2) Sebanyak 31,36\% (82\%) dari $37,94 \%$ anak sakit, karena tidak menerima ASI ekslusif, 3) ASI eksklusif investasi dalam pencegahan Bayi Berat Lahir Rendah (BBLR), stunting dan meningkatkan Inisiasi Menyusu Dini (IMD) dan 4) ASI eksklusif berkontribusi dalam menurunkan risiko obesitas dan penyakit kronis (Patel, 2013).

Pemberian ASI eksklusif dapat mencegah terjadinya stunting, juga dampak dari stunting seperti perkembangan terhambat, penurunan pada perkembangan otak serta kekebalan tubuh, juga risiko menderita penyakit degeneratif saat dewasa. Selain itu bayi yang tidak mendapat ASI eksklusif memiliki risiko kematian karena diare 3,94 lebih besar dibandingkan bayi yang mendapat ASI eksklusif. Hasil penelitian juga menunjukkan bahwa $13,9 \%$ dari semua penyebab kematian bayi dapat dicegah dengan ASI eksklusif untuk 6 bulan pertama kehidupan (Yogantara, 2015).

Meskipun memiliki banyak keunggulan jumlah cakupan bayi mendapatkan ASI eksklusif belum mencapai target dari Kementerian Kesehatan minimal ibu menyusui bayi secara eksklusif yaitu sebesar $80 \%$. Secara nasional, cakupan bayi mendapat ASI eksklusif tahun 2018 adalah sebesar 68,74\%. Untuk Provinsi Riau pencapaian ASI eksklusif tahun 2018 sebesar 35,01\% (Kemenkes, 2019). Data pencapaian ASI eksklusif untuk Kota Pekanbaru juga masih rendah yaitu sebesar $39,06 \%$ pada tahun 2018 dan tahun 2019 cakupan bayi mendapat ASI eksklusif hanya 40,7\%. Pada tingkat kecamatan cakupan pemberian ASI eksklusif di wilayah kerja Puskesmas Senapelan Kecamatan Senapelan pada tahun 2019 dari 587 bayi sebanyak 253 bayi $(43,1 \%)$ mendapat ASI eksklusif, jumlah ini menurun dibandingkan tahun 2018 yaitu dari 503 bayi sebanyak 200 bayi $(39,7 \%)$ yang mendapat ASI eksklusif.

Rendahnya pemberian ASI eksklusif oleh ibu menyusui dapat disebabkan oleh 
faktor karakteristik, internal, dan eksternal. Faktor karakteristik, yaitu umur, pekerjaan dan paritas, faktor internal meliputi rendahnya pengetahuan dan sikap ibu, sedangkan faktor eksternal meliputi kurangnya dukungan keluarga, masyarakat, petugas kesehatan maupun pemerintah, faktor sosial budaya, serta kurangnya ketersediaan fasilitas kesehatan ibu dan anak (Hanifah, 2017).

Paritas ibu merupakan salah satu faktor yang dapat memengaruhi dalam pemberian ASI eksklusif. Primipara adalah wanita yang pertama kali mempunyai anak dan baru menjadi seorang ibu. Dari hasil penelitian ibu yang memiliki paritas primipara mempunyai risiko lebih besar untuk tidak memberikan ASI eksklusif, hal ini disebabkan karena belum memiliki pengalaman dalam menyusui dan perawatan bayi (Hidajati, 2012).

Penelitian Yulianti (2014) menyatakan bahwa paritas berhubungan dengan pemberian ASI eksklusif. Hasil penelitian menunjukkan responden paritas primipara mempunyai peluang 6,889 kali untuk tidak memberikan ASI eksklusif dibanding responden paritas multipara yaitu yang telah melahirkan lebih dari satu kali. Namun meskipun belum ada pengalaman dalam menyusui, keinginan dan keyakinan yang kuat untuk memberikan ASI eksklusif akan mendorong ibu untuk mempelajari hal-hal baru termasuk teknik menyusui yang belum dikuasai benar oleh ibu primipara (Kurniawan, 2013).

Pengetahuan ibu tentang manajemen laktasi merupakan faktor internal yang dapat memengaruhi dalam keberhasilan pemberian ASI eksklusif. Ibu yang memiliki pengetahuan lebih tinggi tentang manajemen laktasi akan menunjukkan kepercayaan diri menyusu yang lebih tinggi dibandingkan ibu yang berpengetahuan rendah (Ratnasari, 2019). Selain itu pada ibu primipara yang memahami pengetahuan manajemen laktasi dengan baik akan memiliki pengalaman menyusui yang menyenangkan dan dapat melaksanakan pemberian ASI eksklusif untuk anak berikutnya. Informasi yang didapat ibu primipara akan memengaruhi perilaku ibu primipara dalam pemberian ASI eksklusif. Pengetahuan dapat diperoleh baik dari pengalaman langsung maupun melalui pengalaman orang lain. Faktor lain yang dapat memengaruhi tinggi rendahnya pengetahuan adalah umur, pendidikan dan informasi yang didapat.

Penelitian Solikhah (2018) diperoleh hubungan antara tingkat pengetahuan manajemen laktasi ibu primipara dengan pemberian ASI eksklusif. Pada penelitian ini ibu menyusui primipara yang memiliki tingkat pengetahuan tinggi, sebagian besar mempunyai manajemen laktasi yang baik.

Faktor eksternal yang dapat memengaruhi perilaku ibu dalam pemberian ASI eksklusif adalah dukungan keluarga. Hal ini disebabkan karena keluarga merupakan orang yang paling dekat dengan ibu dan dapat memengaruhi keadaan emosi ibu maupun perilaku ibu dalam memberikan ASI eksklusif. Dukungan suami dan orang tua adalah support system yang mendorong ibu melakukan dan mempertahankan laktasi, terutama ibu-ibu baru yang akan memulai laktasi (Kurniawan, 2013).

Dukungan keluarga ditandai dengan adanya dukungan emosional yang mencakup empati, kepedulian dan perhatian kepada ibu. Adanya dukungan penilaian yang terjadi lewat ungkapan hormat, dorongan maju atau persetujuan dengan gagasan ibu yang memberikan ASI eksklusif pada bayi. Adanya dukungan instrumental yang mencakup bantuan langsung kepada ibu dan dukungan informasional yang mencakup pemberian nasehat, petunjuk serta saran yang membangun untuk ibu dalam pemberian ASI eksklusif (Takariyana, 2016 dalam Ratnasari, 2019).

Penelitian Arifiati (2012) menunjukkan bahwa adanya hubungan yang bermakna antara dukungan keluarga yaitu suami dan orang tua dengan pemberian ASI eksklusif. 


\section{ISSN 2623-1573 (Print)}

Dukungan keluarga merupakan salah satu faktor keberhasilan pemberian ASI eksklusif. Tidak ada atau kurangnya dukungan dari keluarga terutama dukungan dari suami dan orangtua mengakibatkan ibu tidak memberikan ASI secara eksklusif dan sebaliknya ibu yang mendapat dukungan dari keluarga dapat meningkatkan pemberian ASI eksklusif. Pihak keluarga memegang peranan penting dalam mendukung istri terutama pada ibu primipara yang baru pertama memiliki anak.

Pada survei awal terhadap 9 orang ibu primipara di wilayah kerja Pukesmas Senapelan yang telah melewati masa pemberian ASI eksklusif yaitu ibu yang mempunyai bayi usia 6-12 bulan diperoleh hasil sebanyak 6 orang $(66,7 \%)$ tidak memberikan ASI eksklusif dan sebanyak 3 orang $(33,3 \%)$ memberikan ASI eksklusif kepada bayinya. Dari 6 orang ibu primipara yang belum berhasil memberikan ASI eksklusif sebanyak 6 orang (100\%) memiliki pengetahuan manajemen laktasi yang kurang, dan untuk dukungan keluarga sebanyak 5 orang $(83,3 \%)$ tidak mendapat dukungan keluarga dan hanya 1 orang $(16,7 \%)$ mendapat dukungan keluarga dalam pemberian ASI eksklusif.

Permasalahan yang menyebabkan pembatalan pemberian ASI eksklusif pada 6 orang ibu primipara tersebut antara lain disebabkan karena masalah air susu yang keluar sedikit dan tidak lancar sehingga bayi tidak puas dan sering menangis biarpun sudah menyusu sebanyak 3 orang (50\%), bayi menolak untuk menyusu saat usia 4 bulan sebanyak 1 orang $(16,6 \%)$, masalah pada payudara ibu sebanyak 1 orang $(16,6 \%)$ dan posisi menyusui yang salah sehingga bayi tidak nyaman untuk menyusu sebanyak 1 orang $(16,6 \%)$. Sebab keluarga tidak mendukung ibu dalam pemberian ASI eksklusif karena saat ASI yang keluar sedikit dan tidak lancar keluarga khawatir dengan pertambahan berat badan bayi yang kurang dan menyarankan ibu memberikan susu formula, keluarga juga menganggap bayi sering menangis karena merasa lapar setelah usia 4 bulan sehingga perlu diberi makanan lain selain ASI.

\section{METODE}

Penelitian menggunakan metode penelitian deskriftif dengan rancangan penelitian Cross Sectional yaitu untuk mengetahui hubungan pengetahuan ibu tentang manajemen laktasi dan dukungan keluarga dengan pemberian ASI eksklusif pada bayi usia 0-6 bulan. Penelitian ini dilaksanakan pada April Juni tahun 2020 yang dilaksanakan di wilayah kerja Puskesmas Senapelan yang meliputi 6 kelurahan. Populasi dalam penelitian ini adalah ibu primipara yang memiliki bayi usia 6-12 bulan berjumlah 38 orang. Penelitian ini menggunakan teknik purposive sampling yaitu pengambilan sampel dengan pertimbangan tertentu sesuai dengan tujuan yang dikehendaki. Kriteria sampel adalah ibu primipara yang memiliki bayi usia 6-12 bulan yang telah melewati masa pemberian ASI eksklusif, memiliki suami sah dan tinggal serumah dengan orang tua atau berdekatan.

Data primer pada penelitian ini berupa data pengetahuan ibu tentang manajemen laktasi yang diperoleh dari kuesioner dengan 20 pertanyaan, data dukungan keluarga dari kuesioner dengan 10 pernyataan dan data pemberian ASI eksklusif pada bayi usia 0-6 bulan didapatkan dari pertanyaan dengan metode recall sejak lahir. Analisa data dilakukan secara univariat dan analisa bivariat dengan uji Chi Square.

\section{HASIL}

Data yang dikumpulkan dalam penelitian ini meliputi pengetahuan ibu tentang manajemen laktasi, dukungan keluarga dan pemberian ASI eksklusif pada bayi usia 0-6 bulan.

Karakteristik responden meliputi jenis umur, tingkat pendidikan dan pekerjaan 
ibu. Distribusi berdasarkan karakteristik didapatkan bahwa dari 38 responden, sebanyak 22 responden $(57,9 \%)$ berada pada kategori usia dewasa awal (26-35 tahun), sebanyak 24 responden $(63,2 \%)$ berpendidikan Sekolah Menengah Atas (SMA) dan sebanyak 32 responden $(84,2 \%)$ tidak bekerja/Ibu Rumah Tangga (IRT).

\section{Analisa Univariat}

Analisa univariat dalam penelitian meliputi pengetahuan ibu tentang manajemen laktasi, dukungan keluarga dan pemberian ASI eksklusif pada bayi 0-6 bulan di wilayah kerja Puskesmas Senapelan Kota Pekanbaru.

Hasil analisa data univariat untuk variabel pengetahuan ibu tentang manajemen laktasi dapat dilihat pada grafik 1 berikut ini:

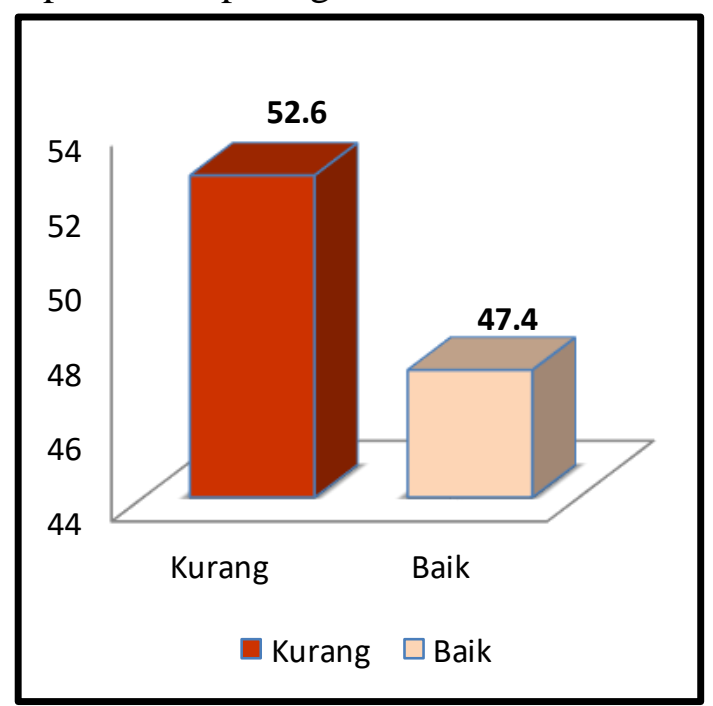

\section{Grafik 1. Pengetahuan Ibu tentang Manajemen Laktasi}

Berdasarkan grafik 1 dari 38 responden sebanyak 20 responden $(52,6 \%)$ memiliki pengetahuan yang kurang tentang manajemen laktasi.

Hasil analisa data univariat untuk variabel dukungan keluarga dapat dilihat pada grafik 3 berikut:

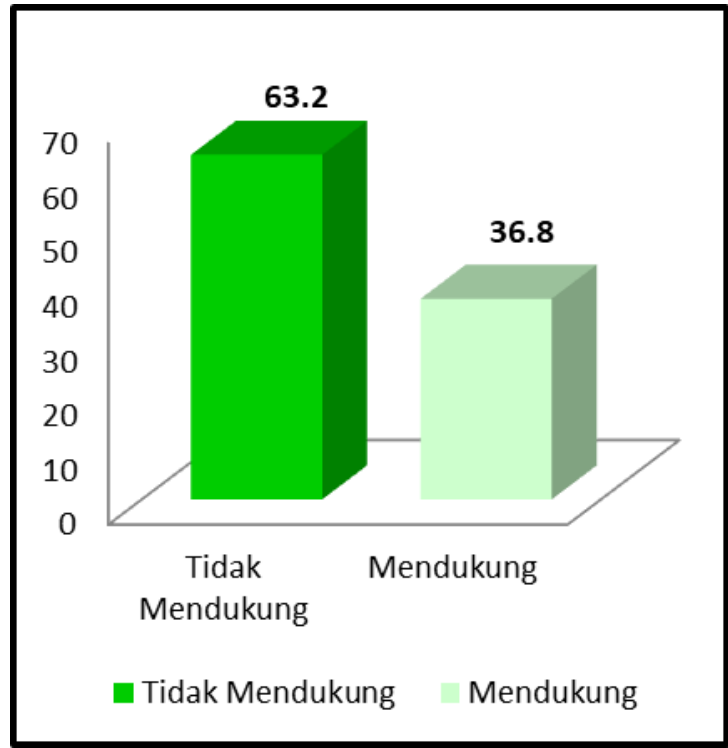

Grafik 2. Distribusi dukungan keluarga

Berdasarkan Grafik 2 dapat dilihat dari 38 responden sebanyak 24 responden $(63,2 \%)$ tidak mendapat dukungan dari keluarga dalam pemberian ASI eksklusif pada bayi usia 0-6 bulan.

Hasil analisa data univariat untuk variabel pemberian ASI eksklusif pada bayi usia 0-6 bulan dapat dilihat pada grafik 3 berikut:

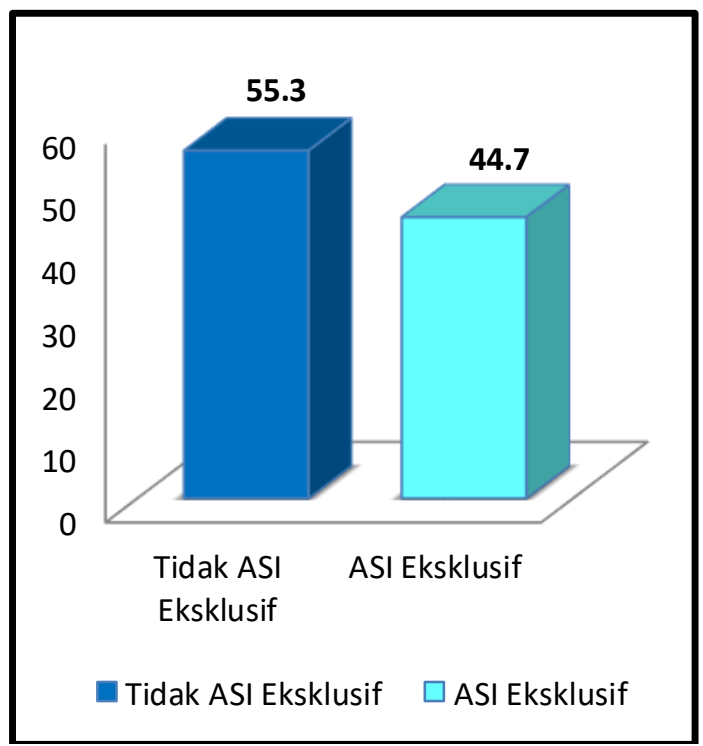

\section{Grafik 3. Pemberian ASI Eksklusif pada Bayi Usia 0-6 bulan}

Berdasarkan grafik dari 38 responden sebanyak 21 responden $(55,3 \%)$ tidak memberikan ASI eksklusif pada bayi usia 0-6 bulan. 


\section{Analisa Bivariat}

Analisa bivariat dilakukan dengan uji Chi Square untuk melihat hubungan pengetahuan ibu tentang manajemen laktasi dan dukungan keluarga dengan pemberian ASI eksklusif pada bayi usia $0-6$ bulan di wilayah kerja Puskesmas Senapelan tahun 2020.

\section{Hubungan Pengetahuan Ibu tentang}

Manajemen Laktasi dengan Pemberian

ASI Eksklusif pada bayi usia 0-6 bulan

Tabel 1. Hubungan Pengetahuan Ibu tentang Manajemen Laktasi dengan Pemberian ASI Eksklusif pada Bayi Usia 0-6 bulan

\begin{tabular}{|c|c|c|c|c|c|c|c|c|c|}
\hline \multirow[t]{3}{*}{ No } & \multirow{3}{*}{$\begin{array}{l}\text { Pengetahuan } \\
\text { Ibu tentang } \\
\text { Manajemen } \\
\text { Laktasi }\end{array}$} & \multicolumn{4}{|c|}{$\begin{array}{c}\text { Pemberian ASI pada Bayi Usia } \\
\text { 0-6 Bln }\end{array}$} & \multicolumn{2}{|c|}{ TOTAL } & \multirow{3}{*}{ POR } & \multirow{3}{*}{ P-Value } \\
\hline & & \multicolumn{2}{|c|}{$\begin{array}{l}\text { Tidak ASI } \\
\text { Eksklusif }\end{array}$} & \multicolumn{2}{|c|}{ ASI Eksklusif } & \multirow[b]{2}{*}{ n } & \multirow[b]{2}{*}{$\%$} & & \\
\hline & & n & $\%$ & n & $\%$ & & & & \\
\hline & Kurang & 15 & 75,0 & 5 & 25,0 & 20 & 100 & $\begin{array}{c}6.000 \\
(1,467-\end{array}$ & \\
\hline & Baik & 6 & 33,3 & 12 & 66,7 & 18 & 100 & 24,547 & 0,024 \\
\hline & TOT & 21 & 55,3 & 17 & 44,7 & 38 & 100 & & \\
\hline
\end{tabular}

Berdasarkan tabel 1 dapat dilihat dari 20 responden yang memiliki pengetahuan kurang tentang manajemen laktasi, sebanyak 5 responden $(25,0 \%)$ memberikan ASI eksklusif kepada bayinya, sedangkan dari 18 responden yang memiliki pengetahuan manajemen laktasi baik, sebanyak 6 responden $(33,3 \%)$ tidak memberikan ASI eksklusif kepada bayinya.

Berdasarkan hasil uji statistik menggunakan uji Chi Square maka diperoleh nilai $p$-value $\leq \alpha(0,05)$ yaitu 0,024 yang artinya ada hubungan yang signifikan antara pengetahuan ibu tentang manajemen laktasi dengan pemberian ASI eksklusif pada bayi usia 0-6 bulan di wilayah kerja Puskesmas Senapelan tahun 2020. Nilai Prevalensi Odd Ratio (POR) yang didapatkan adalah sebesar 6,000 artinya responden dengan pengetahuan manajemen laktasi kurang berpeluang untuk tidak memberikan ASI eksklusif 6 kali
Hasil analisa bivariat hubungan pengetahuan ibu tentang manajemen laktasi dengan pemberian ASI eksklusif pada bayi usia 0-6 bulan dapat dilihat pada tabel 1 berikut ini: lebih besar dibandingkan dengan ibu dengan pengetahuan manajemen laktasi baik dengan nilai $p$-value sebesar 0,013 ( $p$ value $<0,05$ ).

\section{Hubungan Dukungan Keluarga dengan Pemberian ASI Eksklusif pada Bayi usia 0-6 bulan}

Hasil analisa bivariat hubungan dukungan keluarga dengan pemberian ASI eksklusif dapat dilihat pada tabel 2 berikut ini: 
Tabel 2 Hubungan Dukungan Keluarga dengan Pemberian ASI Eksklusif pada Bayi usia 0-6 bulan

\begin{tabular}{|c|c|c|c|c|c|c|c|c|c|}
\hline \multirow{3}{*}{ No } & \multirow{3}{*}{$\begin{array}{l}\text { Dukungan } \\
\text { Keluarga }\end{array}$} & \multicolumn{4}{|c|}{ Pemberian ASI Eksklusif } & \multirow{2}{*}{\multicolumn{2}{|c|}{ TOTAL }} & \multirow{3}{*}{ POR } & \multirow{3}{*}{ P-Value } \\
\hline & & \multicolumn{2}{|c|}{$\begin{array}{l}\text { Tidak ASI } \\
\text { Eksklusif } \\
\end{array}$} & \multicolumn{2}{|c|}{ ASI Eksklusif } & & & & \\
\hline & & $\mathbf{n}$ & $\%$ & $\mathbf{n}$ & $\%$ & $\mathbf{n}$ & $\%$ & & \\
\hline & Tidak Mendukung & 17 & 70,8 & 7 & 29,2 & 24 & 100 & $\begin{array}{c}6.071 \\
(1,416-\end{array}$ & 0,029 \\
\hline & $2 \quad$ Mendukung & 4 & 28,6 & 10 & 71,4 & 14 & 100 & 26,033 & \\
\hline \multicolumn{2}{|c|}{ TOT A L } & 21 & 55,3 & 17 & 44,7 & 38 & 100 & & \\
\hline
\end{tabular}

Berdasarkan tabel 2 dapat dilihat dari 24 respon den yang tidak mendapat dukungan dari keluarga, sebanyak 7 responden $(29,2 \%)$ memberikan ASI eksklusif kepada bayinya, sedangkan dari 14 responden yang mendapat dukungan dari keluarga, sebanyak 4 responden $(28,6 \%)$ tidak memberikan ASI eksklusif kepada bayinya.

Berdasarkan hasil uji statistik menggunakan uji Chi Square maka diperoleh nilai $p$-value $\leq \alpha(0,05)$ yaitu 0,029 yang artinya ada hubungan yang signifikan antara dukungan keluarga dengan pemberian ASI eksklusif pada bayi usia 0-6 bulan di wilayah kerja Puskesmas Senapelan tahun 2020. Sedangkan nilai Prevalensi Odd Ratio (POR) adalah 6,071, artinya responden yang keluarganya tidak mendukung dalam pemberian ASI eksklusif memiliki peluang 6,071 kali lebih besar untuk tidak memberikan ASI eksklusif kepada bayinya dengan nilai p-value sebesar 0,015 ( $p$-value $<0,05)$.

\section{PEMBAHASAN}

\section{Hubungan Pengetahuan Ibu tentang Manajemen Laktasi dengan Pemberian ASI Eksklusif pada bayi usia 0-6 bulan}

Pada hasil analisa bivariat dari 20 responden yang memiliki pengetahuan kurang tentang manajemen laktasi, sebanyak 5 responden $(25,0 \%)$ memberikan ASI eksklusif kepada bayinya, sedangkan dari 18 responden yang memiliki pengetahuan manajemen laktasi baik, sebanyak 6 responden $(33,3 \%)$ tidak memberikan ASI eksklusif kepada bayinya.

Menurut asumsi peneliti ibu yang memiliki pengetahuan kurang namun tetap memberikan ASI eksklusif disebabkan karena niat ibu yang kuat untuk memberikan yang terbaik bagi bayinya terutama pada ibu primipara yang umumnya memiliki kepedulian untuk memenuhi kebutuhan bayi dan dalam hal pemberian ASI untuk bayi pertamanya. Niat ibu yang kuat dalam pemberian ASI eksklusif akan dapat mendorong timbulnya kepercayaan diri ibu dalam menyusui. Kepercayaan diri ibu yang tinggi ditandai dengan yakin akan produksi ASI sehingga dapat mencapai keberhasilan dalam memberikan ASI eksklusif.

Pada ibu dengan ekonomi rendah yang mengetahui manfaat ASI untuk pertumbuhan dan perkembangan bayi juga akan berusaha untuk memberikan ASI saja sampai usia 6 bulan. Sesuai dengan manfaat ASI yang ekonomis dan praktis akan membantu menghemat pengeluaran karena dengan pemberian ASI ibu tidak perlu membeli perlengkapan menyusui dan susu formula yang harganya mahal. Pemberian ASI juga praktis sehingga ibu dapat memberikan ASI kapan saja dan dimana saja sesuai keinginan bayi tanpa perlu menyiapkan botol susu dan membuat susu formula.

Berbeda dengan ibu yang memiliki pengetahuan manajemen laktasi baik namun tidak memberikan ASI eksklusif kepada bayinya disebabkan karena faktor stress dan kelelahan yang dapat 
memengaruhi produksi ASI. Pada ibu usia muda yang baru saja melahirkan dan baru belajar merawat bayi akan mengalami perubahan jadwal istirahat dan tidur karena ibu memiliki tugas baru menjaga dan menyusui bayi on demand sehingga tidak jarang membuat tubuh menjadi lelah dan letih.

Rasa lelah dan letih tersebut harus diatasi dengan mengatur waktu tidur karena rasa capek dan lelah menjadikan badan tidak segar dimana hal tersebut berpengaruh pada produksi ASI sehingga ASI yang keluar sedikit dan tidak lancar. Pada ibu yang khawatir tidak dapat memenuhi kebutuhan bayi di malam hari dan ibu yang memiliki pendapat bahwa ASI yang dimilikinya belum mampu membuat bayi kenyang akan cenderung memberikan susu kombinasi antara susu formula dan ASI bahkan susu formula saja ke bayinya.

Faktor pengetahuan dan informasi yang didapat akan memengaruhi niat seorang ibu untuk memberikan ASI eksklusif. Niat adalah kehendak atau keinginan dalam hati seseorang ingin melakukan sesuatu perilaku. Niat erat kaitannya dengan motivasi, yaitu dorongan yang timbul dalam diri seseorang secara sadar untuk melakukan suatu tindakan dengan tujuan tertentu. Seseorang akan memiliki niat yang kuat jika informasi yang dimilikinya cukup kuat untuk meyakinkannya bahwa perilaku tersebut layak untuk dilakukan. Niat yang sudah dimiliki seseorang, hendaknya diperkuat dengan menambah pengetahuan mengenai ASI baik keunggulan, komposisi, manfaat, dan keutamaannya. Pengetahuan diperlukan untuk memantapkan niat ibu untuk memberikan ASI (Nurani, 2013 dalam Yusrina, 2016).

Tingkat pendidikan menentukan mudah atau tidaknya seseorang untuk memahami serta menyerap pengetahuan yang diperoleh dan juga berpengaruh dalam memberikan respon, semakin ibu berpendidikan tinggi maka akan memberikan respon yang lebih rasional terhadap informasi yang ada. Pada umumnya, semakin tinggi pendidikan semakin tinggi pula pengetahuan yang dimiliki. Usia juga merupakan faktor yang memengaruhi pengetahuan, ibu dengan usia yang lebih tua dianggap memiliki pengalaman dalam hal menyusui yang lebih banyak dibandingkan dengan ibu usia muda, sehingga pengetahuannya pun lebih baik dibandingkan dengan ibu usia muda.

Pengetahuan manajemen laktasi erat hubungannya dengan pemberian ASI eksklusif pada bayi usia 0-6 bulan karena responden yang memiliki pengetahuan kurang tentang upaya yang dilakukan dalam menunjang keberhasilan menyusui akan mudah terpengaruh memberikan makanan tambahan apabila ada masalah dalam menyusui dan merasa putus asa bila timbul masalah seperti ASI tidak keluar, ASI sedikit/tidak lancar dan adanya masalah pada saat menyusui.

Penelitian ini sejalan dengan yang dilakukan Kurniasih (2015) yaitu hubungan tingkat pengetahuan ibu tentang manajemen laktasi dengan pemberian ASI eksklusif di desa Blingo kecamatan Ngluwar Kabupaten Magelang. Populasi penelitian adalah ibu yang memiliki bayi usia 6-12 bulan berjumlah 44 orang, dan sampel diambil dengan teknik sampling jenuh yaitu sebanyak 44 responden. Hasil penelitian adalah ibu memiliki tingkat pengetahuan manajemen laktasi dalam kategori cukup sebanyak 22 orang $(50 \%)$ dan ibu tidak memberikan ASI eksklusif sebanyak 24 orang (54.5\%). Hasil uji statistik Chi Square diperoleh nilai $\mathrm{x}^{2}$ hitung sebesar 23.467 dan signifikan 0.000 ( $p$-value <0.05). Kesimpulan penelitian ada hubungan tingkat pengetahuan ibu tentang manajemen laktasi dengan pemberian ASI Eksklusif di Desa Blingo, Kecamatan Ngluwar, Kabupaten Magelang.

Penelitian lain adalah yang dilakukan Priatna (2020) dengan judul pengetahuan ibu tentang manajemen laktasi dengan perilaku pemberian ASI ekslusif yang dilakukan di diwilayah kerja Puskemas 
Gembor Tangerang tahun 2019. Penelitian ini merupakan jenis penelitian kuantitatif dengan desain deskriptif kolerasi. Pengumpulan data dilakukan dengan kuesioner. Jumlah responden sebanyak 89 orang ibu yang memiliki bayi berusia 6-12 bulan dengan teknik simple random sampling. Data yang diperoleh diolah secara statistik dengan menggunakan rumus Chi Square. Hasil analisis pengetahuan ibu tentang manajemen laktasi dengan perilaku pemberian ASI eksklusif, diperoleh $p$ value $=0,011$ sehingga ada hubungan yang bermakna antara pengetahuan manajemen laktasi dengan perilaku pemberian ASI eksklusif.

\section{Hubungan Dukungan Keluarga dengan Pemberian ASI Eksklusif pada bayi usia 0-6 bulan di wilayah kerja Puskesmas Senapelan}

Pada hasil analisa dapat dilihat dari 24 responden yang tidak mendapat dukungan keluarga, sebanyak 7 responden $(29,2 \%)$ memberikan ASI eksklusif kepada bayinya, sedangkan dari 14 responden yang mendapat dukungan keluarga, sebanyak 4 responden $(28,6 \%)$ tidak memberikan ASI eksklusif kepada bayinya.

Menurut asumsi peneliti ibu yang tidak mendapat dukungan keluarga namun memberikan ASI eksklusif kepada bayinya disebabkan karena sebagian besar responden memiliki pendidikan tinggi. Semakin tinggi tingkat pendidikan seseorang, maka semakin mudah pula seseorang untuk menerima informasi. Informasi yang didapat seseorang nantinya akan memengaruhi pengetahuan (Kurniawati, 2014). Dan akhirnya akan memengaruhi perilaku seseorang sehingga mampu menumbuhkan kesadaran ibu dalam pemberian ASI eksklusif.

Saat ini tidak menjadi halangan bagi seorang ibu yang berstatus sebagai Ibu Rumah Tangga (IRT) untuk meningkatkan pengetahuan tentang manajemen laktasi. Sebab seiring berkembangnya teknologi ibu yang berstatus sebagai IRT tetap dapat memperoleh informasi secara mandiri melalui berbagai sumber media khususnya yang berbasis internet sehingga dapat memberikan informasi tentang manajemen laktasi sebagai salah satu upaya menumbuhkan kesadaran perilaku pemberian ASI eksklusif kepada bayi usia 0-6 bulan.

Faktor lain juga dapat disebabkan keinginan meniru meliputi keberhasilan teman dalam memberikan ASI eksklusif. Teman dapat menjadi dorongan terkuat ibu dalam memberikan ASI eksklusif, dalam hal ini ibu melihat pertumbuhan bayi mereka yang diberi ASI eksklusif tumbuh sehat, maka hal ini akan mendorong ibu melakukan hal yang sama pada bayinya

Sebaliknya pada ibu yang mendapat dukungan keluarga namun tidak memberikan ASI eksklusif kepada bayinya dapat disebabkan karena kurangnya kepercayaan diri ibu dalam menyusui sehingga ibu tidak tenang dan mengakibatkan posisi menyusui yang salah. Bila ibu merasa ragu atau kurang percaya diri dapat menyebabkan kerja hormon oksitosin yang memproduksi ASI melambat dan akibatnya ASI yang keluar menjadi sedikit. Ibu menyusui sebaiknya menguasai teknik menyusui yang benar. Kegagalan dalam menyusui seringkali disebabkan oleh kesalahan posisi menyusui sehingga menyebabkan puting ibu lecet dan akhirnya ibu menjadi enggan untuk menyusui.

Hal lain dapat juga disebabkan pada ibu yang memerhatikan penampilan terutama ibu muda akan khawatir terlihat tidak cantik dan payudara menjadi kendur akibat menyusui sehingga ibu menolak menyusui bayinya meskipun mendapat dukungan dari keluarga. Kegiatan menyusui bayi memang akan memengaruhi bentuk payudara, namun menyusui bukanlah penyebab utamanya.

Faktanya payudara menjadi kendur disebabkan oleh bertambahnya usia dan kehamilan. Saat hamil, hormon-hormon menambah kelenjar ASI sehingga membuat 


\section{ISSN 2623-1573 (Print)}

ukuran payudara lebih besar dari ukuran biasanya. Setelah masa manyusui selesai, ukuran payudara akan kembali normal dengan melakukan senam payudara atau pemilihan bra yang tepat.

Setelah dilakukan uji statistik menggunakan uji Chi Square maka diperoleh nilai $\mathrm{p}$-value $\leq \alpha(0,05)$ yaitu 0,029 yang artinya ada hubungan yang signifikan antara dukungan keluarga dengan pemberian ASI eksklusif pada bayi usia 0-6 bulan di wilayah kerja Puskesmas Senapelan tahun 2020.

Dukungan keluarga adalah dukungan yang diberikan keluarga untuk memotivasi ibu agar memberikan ASI eksklusif kepada bayi. Dukungan keluarga merupakan salah satu faktor keberhasilan pemberian ASI eksklusif. Soetjiningsih (2010) mengemukakan dukungan sosial dari lingkungan sekitar ibu mempunyai peran besar dalam keberhasilan menyusui. Keluarga dengan tingkat pengetahuan baik mengenai ASI eksklusif akan mendukung ibu agar memberikan ASI kepada bayinya.

Interaksi positif dengan keluarga akan menimbulkan kasih sayang dan dukungan moril. Ibu menyusui membutuhkan keluarga untuk dapat membantu ibu dalam merawat bayi dan membantu ibu dalam pekerjaan rumah, sehingga ibu merasa mendapatkan dukungan dari keluarganya untuk dapat menyusui bayinya (Hanifah, 2017). Anggota keluarga yaitu suami dan orang tua dianggap sebagai pihak yang paling mampu memberikan pengaruh kepada ibu untk memaksimalkan pemberian ASI eksklusif (Trisnawati, 2018).

Semakin besar dukungan yang didapatkan akan semakin besar kemampuan untuk dapat bertahan terus menyusui. Ibu yang berada dalam keadaan tenang akan memiliki pikiran positif terhadap bayi sehingga ibu merasa senang saat melihat bayi, kemudian memikirkan bayi dengan penuh kasih sayang dan ingin memberikan ASI kepada bayinya.
Keadaan tenang dapat diperoleh jika ibu mendapatkan dukungan dari lingkungan sekitar yaitu suami, orangtua, maupun keluarga lainnya agar ibu memberikan ASI eksklusif kepada bayi (Hedianti et al, 2017). Persiapan psikologi ibu sangat menentukan keberhasilan menyusui. Ibu yang tidak mempunyai keyakinan mampu memproduksi ASI umumnya menyebabkan produksi ASI akan berkurang. Stress, khawatir dan ketidak bahagiaan ibu pada periode menyusui sangat berperan dalam pemberian ASI ekslusif karena itu peran keluarga dalam meningkatkan percaya diri ibu sangat besar (Ja'far, 2011).

Rasa percaya diri yang dimiliki oleh ibu dalam menyusui dapat menjadi penyebab apakah ibu akan memutuskan untuk menyusui, sebesar apa upaya yang dilakukan untuk menyusui, apakah ibu mempunyai pola pikir membangun atau merusak dan bagaimana cara merespons berbagai masalah dan kesulitan selama menyusui (Pradanie, 2015 dalam Ratnasari, 2019).

Dengan demikian dukungan keluarga memiliki pengaruh terhadap pemberian ASI eksklusif terutama pada ibu primipara yang belum memiliki pengalaman menyusui. Seorang ibu yang tidak pernah mendapatkan informasi mengenai ASI eksklusif dari keluarga dapat memengaruhi sikap ibu saat menyusui dan dukungan keluarga yang baik dapat terwujud dengan membentuk keyakinan positif ibu terhadap pemberian ASI eksklusif.

Seorang ibu yang memiliki keluarga yang kurang pemahaman mengenai ASI eksklusif akan merasa tidak enak apabila tidak menuruti saran dari keluarga sehingga ibu memberikan makanan selain ASI kepada bayi sebelum usia 6 bulan. Contohnya kebiasaan masyarakat untuk memberikan makanan tambahan seperti pisang kepada bayi dengan alasan jika diberi ASI saja bayi tidak akan kenyang dan akan menangis terus. Namun apabila keluarga memahami pentingnya ASI eksklusif maka keluarga akan membantu 
ibu bila ada masalah dalam menyusui juga dalam memberikan informasi pentingnya ASI eksklusif, menyenangkan hati ibu, dan mengingatkan ibu untuk menyusui bayi tanpa menambahkan dengan makanan lain selain ASI.

Penelitian ini sejalan dengan yang dilakukan Arifiati (2017) tentang Analisis Faktor yang Memengaruhi Pemberian ASI Ekslusif pada Bayi di Kelurahan Warnasari Kecamatan Citangkil Kota Cilegon. Sampel pada penelitian ini adalah ibu yang mempunyai bayi usia 6-12 bulan berjumlah 55 orang. Hasil penelitian menunjukkan proporsi responden yang mendapat dukungan keluarga dan memberikan ASI ekslusif sebesar $69.2 \%$. Jumlah tersebut lebih tinggi dibandingkan responden yang tidak mendapat dukungan keluarga namun memberikan ASI ekslusif (9.5\%). Kondisi tersebut menunjukan bahwa dukungan keluarga akan memengaruhi pemberian ASI ekslusif terhadap bayi. Dari hasil uji Chi Square didapatkan hasil 0,000 ( $p$ value $\leq 0,05)$. Dengan demikian penelitian ini terbukti ada hubungan antara dukungan keluarga dengan pemberian ASI ekslusif.

Penelitian ini sejalan pula dengan penelitian Yusro et al (2017) tentang hubungan peran tenaga kesehatan dan dukungan keluarga dengan perilaku pemberian ASI eksklusif ibu primipara di wilayah Kerja Puskesmas Pringapus Kabupaten Semarang. Sampel pada penelitian adalah ibu primipara dengan jumlah responden sebanyak 42 responden. Hasil penelitian menunjukkan responden yang mendapat dukungan keluarga sebanyak 15 responden $(93,8 \%)$ memberikan ASI eksklusif, lebih besar dibandingkan yang tidak memberikan ASI eksklusif yaitu sebanyak 9 responden $(34,6 \%)$. Sedangkan responden yang tidak mendapat dukungan keluarga sebanyak 1 responden $(6,2 \%)$ memberikan ASI eksklusif, lebih sedikit dibandingkan yang tidak memberikan ASI eksklusif sebanyak 17 responden $(65,4 \%)$. Hal ini berarti ada pengaruh dukungan keluarga terhadap responden yang memberikan ASI eksklusif. Hasil uji Chi Square ada hubungan bermakna antara dukungan keluarga dengan perilaku pemberian ASI eksklusif ibu primipara di wilayah Kerja Puskesmas Pringapus Kabupaten Semarang dengan nilai 0,001 ( $p$ value $\leq 0,05)$.

\section{KESIMPULAN}

Sebagian besar pengetahuan ibu tentang manajemen laktasi berada pada kategori kurang, sebagian besar keluarga tidak mendukung responden dalam pemberian ASI eksklusif pada bayi usia 0-6 bulan dan sebagian besar responden tidak memberikan ASI eksklusif pada bayi usia 0-6 bulan.

Ada hubungan yang signifikan antara pengetahuan ibu tentang manajemen laktasi dan dukungan keluarga dengan pemberian ASI eksklusif pada bayi usia 0-6 bulan di wilayah kerja Puskesmas Senapelan tahun 2020.

\section{DAFTAR PUSTAKA}

Arifiati, N. (2017). Analisis Faktor yang Memengaruhi Pemberian Asi Ekslusif pada Bayi di Kelurahan Warnasari Kecamatan Citangkil Kota Cilegon. In Prosiding Seminar Nasional IKAKESMADA "Peran Tenaga Kesehatan dalam Pelaksanaan SDGs". Fakultas Kesehatan Masyarakat Universitas Ahmad Dahlan.

Hanifah, S. A., Astuti, S., \& Susanti, A. I. (2017). Gambaran Karakteristik Ibu Menyusui Tidak Memberikan ASI Eksklusif di Desa Cikeruh Kecamatan Jatinangor Kabupaten Sumedang Tahun 2015. Jurnal Sistem Kesehatan, 3(1).

Hedianti, D. A., Sumarmi, S., \& Muniroh, L. (2015). Dukungan Keluarga dan Praktik Pemberian ASI Eksklusiif di Puskesmas Pucang Sewu. Jurnal Kesehatan Masyarakat Universitas Airlangga. 


\section{ISSN 2623-1573 (Print)}

Ibrahim et al (2014). Gambaran Pengetahuan dan Sikap Ibu tentang Manajemen Laktasi di Wilayah Kerja Puskesmas Samaenre Kabupaten Sinjai tahun

2014. Public Health Science Journal Vol. VI, No. 2, Juli-Desember 2014.

Kemenkes RI. (2019). Peraturan Menteri Kesehatan No. 43 tahun 2019 tentang Pusat Kesehatan Masyarakat. Jakarta: Kementerian Kesehatan RI.

Kurniasih, D. \& Ismarwati, I. (2015). Hubungan Tingkat Pengetahuan Ibu tentang Manajemen Laktasi dengan Pemberian ASI EKsklusif di Desa Bligo Kecamatan Ngluwar Kabupaten Magelang (Doctoral Dissertation, STIKES Aisyiyah Yogyakarta).

Kurniawati. (2014). Faktor Determinan yang Memengaruhi Kegagalan Pemberian ASI Eksklusif pada Bayi Usia 6-12 Bulan di Kelurahan Mulyorejo Wilayah Kerja Puskesmas Mulyorejo Surabaya. Jurnal Promkes, Vol. 2 No. 1, Juli 2014 : 15-27.

Kurniawan, Bayu. (2013). Determinan Keberhasilan Pemberian Air Susu Ibu Eksklusif. Jurnal kedokteran Brawijaya, Vol. 27, No. 4.

Priatna, H., \& Nurafiah, E. (2020). Pengetahuan Ibu Tentang Manajemen Laktasi Dengan Perilaku Pemberian ASI Ekslusif. Jurnal Kesehatan, 9(1), 33-43.

Puskesmas Senapelan. (2020). Profil Puskesmas Tahun 2019. Pekanbaru.

Patel \& Gedam (2013). Effeck Back Massage On Lactation Among Postnatal Mother. India.

Ratnasari, R. D. (2019). Faktor-Faktor yang Memengaruhi Kepercayaan Diri Ibu pada Pemberian ASI Eksklusif di Wilayah Desa Sentolo Kulon Progo Yogyakarta (Doctoral Dissertation, Universitas' Aisyiyah Yogyakarta).

Solikhah, P.R. (2018). Faktor-faktor yang Berhubungan dengan Manajemen Laktasi pada ibu primipara di
Wilayah Puskesmas Nusukan Banjarsari Kota Surakarta. Skripsi. Universitas Muhammadiyah.

Trisnawati, E., \& Widyastutik, (2018).

Kegagalan ASI Eksklusif:

Manajemen Laktasi dan Dukungan

Keluarga. Jurnal Formil KesMAs

Respati, Volume 3, Nomor2,

Yogantara, A. M. (2018). Kegagalan

Pemberian ASI Eksklusif pada Bayi

Usia 0-6 Bulan di Wilayah

Puskesmas Manggis I

Karangasem. Intisari Sains

Medis, 3(1), 70-75.

Yulianti, F, (2014). Hubungan antara Karakteristik, Tingkat Pengetahuan dan Dukungan Keluarga terhadap Pemberian ASI Eksklusif di Wilayah

Kerja Puskesmas Siantan Hulu Kecamatan Pontianak Utara Tahun 2014, Jurnal Mahasiswa Fakultas Kedokteran Universitas Tanjungpura, Vol 1 No 1

Yusrina. (2016). Faktor Yang Memengaruhi Niat Ibu Memberikan ASI Eksklusif di Kelurahan Magersari, Sidoarjo. Jurnal Promkes, Vol. 4, No. 1, 11-21.

Yusro, Arizki Nafi'atul, et al. (2017).Hubungan Peran Tenaga Kesehatan dan Dukungan Keluarga dengan Perilaku Pemberian ASI Eksklusif Ibu Primipara di Wilayah Kerja Puskesmas Pringapus Kabupaten Semarang: Prodi DIV Kebidanan Semarang Poltekkes Kemenkes Semarang. 